\title{
From Pre-Existing Renal Failure to Perioperative Renal Protection: The Anesthesiologist's Dilemmas
}

\author{
Rudin Domi, ${ }^{1,}$ Gentian Huti, ${ }^{2}$ Hektor Sula, ${ }^{1}$ Nehat Baftiu, ${ }^{3}$ Myzafer Kaci, ${ }^{1}$ Artan Bodeci, ${ }^{1}$ and Albert \\ Pesha $^{4}$ \\ ${ }^{1}$ Department of Anesthesiology and Intensive Care Medicine, “Mother Teresa” University Hospital Center, Faculty of Medicine, Medical University of Albania, Tirana, Albania \\ ${ }^{2}$ Department of Anesthesia, American Hospital, Tirana, Albania \\ ${ }^{3}$ Clinic of Anesthesiology and Intensive Care, University Clinic Center, Faculty of Medicine, "Hasan Prishtina” University, Prishtine, Kosovo \\ ${ }^{4}$ Clinic of Surgery, Regional Hospital, Fier, Albania \\ "Corresponding author: Rudin Domi, Department of Anesthesiology and Intensive Care Medicine, "Mother Teresa" University Hospital Center, Faculty of Medicine, Medical \\ University of Albania, Tirana, Albania. Tel: +355-682067003, E-mail: rdomi73@yahoo.it
}

Received 2015 August 25; Revised 2015 September 26; Accepted 2015 October 17.

\begin{abstract}
Context: Pre-existing renal dysfunction presents specific features that anesthesiologists must deal with. Anesthesia and renal function are connected and can interfere with each other. Induced hypotension anesthesia and the toxic effects of anesthetic drugs can further deteriorate renal function.

Evidence Acquisition: Decreased renal function can prolong anesthetic drug effects by decreased elimination of these drugs. Anesthesia can deteriorate renal function and decreased renal function can interfere with drug elimination leading to their prolonged effect. The anesthesiologist must understand all the physiological aspects of the patient, renal protection, and the relationships between anesthetic drugs and renal function. This review article aims to summarize these aspects.

Results: Perioperative renal failure and renal protection is a crucial moment in clinical practice of every anesthesiologist.

Conclusions: Good knowledges for renal function remain a hallmark of daily practice of the anesthesiologist, considering renal function as an important determinant factor in anesthesia practice.
\end{abstract}

Keywords: Anesthesia, Acute Kidney Injury, Renal Protection

\section{Context}

Managing a patient with pre-existing renal dysfunction, who is undergoing surgery and anesthesia, presents a unique challenge to the anesthesiologist. A strict preoperative evaluation and optimization can reduce morbidity and mortality. Optimization of the patient with renal dysfunction need not only consider pre-existing renal function but also can reduce the possibility of acute kidney injury (AKI) in the post-operative period.

\section{Evidence Acquisition}

\subsection{Current Definitions and Terminology}

\subsubsection{Chronic Kidney Disease (CKD)}

The kidney disease outcomes quality initiative (K/DOQI) defined CKD in 2002 (1) as either kidney damage or decreased kidney function for three or more months. The national kidney foundation classifies CKD (2) based on pathology: diabetic glomerulosclerosis, glomerular diseases (primary or secondary), vascular diseases (including hypertension and microangiopathy), tubulointerstitial diseases (including obstructive or reflux nephropathy), cystic diseases, and diseases in renal transplant recipients (rejection, drug toxicity, recurrence of disease) (3).

A glomerular filtration ratio (GFR) of less than 60 $\mathrm{mL} /$ minute/1.73 $\mathrm{m}^{2}$ has been recently accepted as borderline for CKD, but renal failure can be defined as GFR less than $15 \mathrm{~mL} /$ minute $/ 1.73 \mathrm{~m}^{2}$ or requiring renal replacement therapy or transplantation (3).

\subsubsection{Acute Kidney Injury (AKI)}

In an effort to standardize the classification of AKI, in 2004 the acute dialysis quality initiative (ADQI) group proposed the RIFLE (4) criteria representing: risk of renal dysfunction (R); injury to the kidney (I); failure of kidney function (F); loss of kidney function (L); and end-stage kidney disease (E). The RIFLE criteria is based on estimation of GFR, serum creatinine level (SCr), and urine output (UO) in order to classify the severity of AKI.

AKI can also be classified as pre-renal, renal, and postrenal. Perioperatively, the most common form of AKI is due to acute tubular necrosis (ATN). A study in intensive care unit (ICU) patients found the most common causes of 
AKI were sepsis, major and prolonged surgery, cardiogenic shock, hypovolemia, and finally, drug-induced AKI.

In 2007 the acute kidney injury network (AKIN) proposed a modification to the RIFLE criteria (5). Table 1 (5) summarizes these changes.

Table 1. Classification of AKI (5)

\begin{tabular}{lcc}
\hline Stages & Serum Creatinine Criteria & Urine Output Criteria \\
\hline $\mathbf{1}$ & $\uparrow \mathrm{SCr} 150-200 \%$ over baseline & UO $0.5 \mathrm{~mL} / \mathrm{kg}$ for $6 \mathrm{~h}$ \\
$\mathbf{2}$ & $\uparrow \mathrm{SCr} 200-300 \%$ over baseline & UO $0.5 \mathrm{~mL} / \mathrm{kg}$ for $12 \mathrm{~h}$ \\
$\mathbf{3}$ & $\uparrow \mathrm{SCr}$ more than $300 \%$ or more & UO $0.3 \mathrm{~mL} / \mathrm{kg}$ for $24 \mathrm{~h}$ or anuria \\
& than 4.0 & for $12 \mathrm{~h}$
\end{tabular}

Despite their use in the current definitions of AKI, $\mathrm{SCr}$ and UO are not the ideal markers for AKI, and new potential biomarkers (under study) of AKI include neutrophil gelatinase-associated lipocalin (NGAL), cystatin C, and interleukin-18.

\section{Results}

\subsection{Preoperative Evaluation and Preparation}

Depending on the patient's status and the surgical procedure, the preoperative evaluation may require close communication between the primary care physician, nephrologist, surgeon, and anesthesiologist to determine if a patient is optimized for surgery. The national kidney foundation recommends the following assessments for patients with CKD: diagnosis (type of kidney disease), comorbid conditions, severity of CKD assessed by level of kidney function, complications related to level of kidney function, risk for loss of kidney function, and risk for cardiovascular disease (1).

Comorbid conditions are generally underlying causes like diabetes or hypertension. A strict screening of these diseases is strongly recommended before surgery. Complications related to renal function (6) are summarized in Table 2 .

The risk for cardiovascular complications should be promptly evaluated. The patient should undergo a routine electrocardiogram and often a cardiopulmonary exercise test, in order to identify high-risk patients. All present preoperative abnormalities, such as anemia, hyperkalemia, and metabolic acidosis, should be preoperatively corrected. A hemoglobin value of $10 \mathrm{~g} / \mathrm{dl}$ is strongly recommended (7). Hyperkalemia is to be corrected, especially, if electrocardiogram signs, such as bradycardia, peaked T wave, or QRS prolongation, are present. Calcium chloride, insulin and dextrose, sodium bicarbonate, and
Table 2. Systemic Effects of Renal Failure

\begin{tabular}{lc}
\hline System & Effects \\
\hline Cardiovascular system & $\begin{array}{c}\text { Hypertension, ischemic heart disease, } \\
\text { pericarditis, heart failure }\end{array}$ \\
\hline Respiratory system & $\begin{array}{c}\text { Pulmonary edema, pleural effusion, respiratory } \\
\text { infection }\end{array}$ \\
\hline Central nervous system & Autonomic neuropathy, coma \\
\hline Hematological & Anemia, bleeding tendency \\
\hline Gastro-intestinal & Stress ulceration, delayed gastric emptying \\
\hline Renal and metabolic & Fluid retention, hyperkalemia, metabolic \\
ammunological aspects
\end{tabular}

resins can be used to correct hyperkalemia (7). If the patient is under dialysis treatment, the final dialysis prior to surgery should be scheduled $12-24$ hours before surgery. After the dialysis, several negative effects are faced, such as dehydration, hypokalemia, and residual anticoagulation as a result of heparin use. These negative effects can induce profound hypotension after the anesthesia induction and increase intraoperative bleeding.

\subsection{Anesthetic Management}

The anesthetic management of patients suffering from CKD is complex. Due to delayed gastric emptying and neuropathy, there is risk of gastric acid aspiration. Gastric aspiration prophylaxis can be managed using sodium citrate, metoclorpramide, anti-H2 drugs, and rapid induction (7). It is recommended choosing short-acting anesthetic drugs (propofol, remifentanil, cisatracurium, vecuronium) and at the same time not depending on renal metabolization and excretion. Sevoflurane can deteriorate renal function by fluoride ions and compound A production, so isoflurane remains the preferred anesthetic inhalator agent. After the induction, hypotension is often present. This hypotension can be explained by reduced blood volume (dialysis, diuretics), preoperative chronic antihypertensive drugs, autonomic neuropathy, anesthetic drugs, and mechanical ventilation (positive pressure) (8). So, patients with CKD that do not require dialysis, or those at high risk for postoperative renal failure, must benefit by careful preoperative fluid optimization. Standard monitoring is generally used, but invasive monitoring and central venous access may be required in severe cases with cardiac comorbidities. Arteriovenous fistulas may be protected by avoiding blood pressure measuring and arterial or venous puncture in the proper arm. Using regional anesthesia (when appropriate) can avoid systemic endovenous anesthetic drugs. 


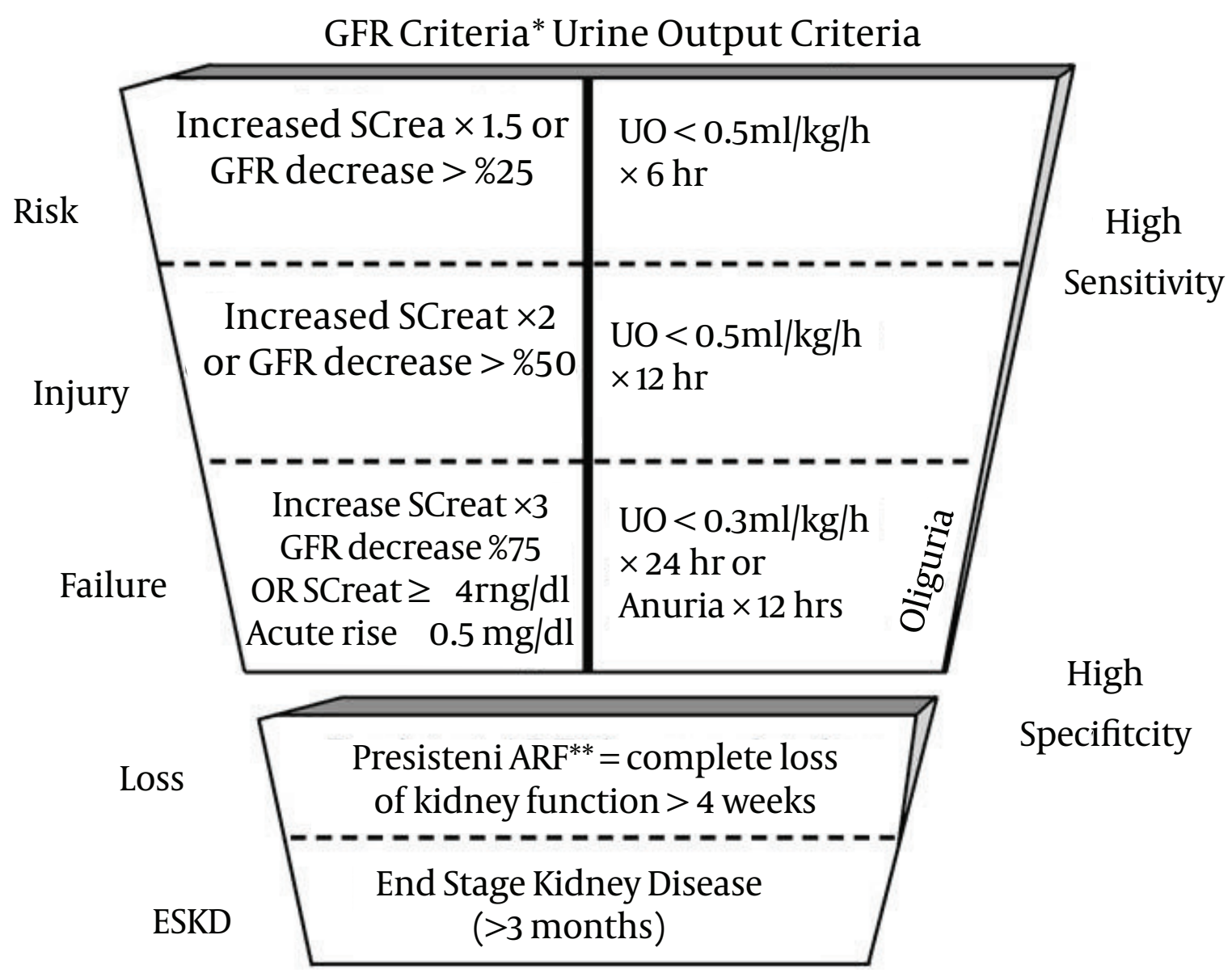

Figure 1. RIFLE Classification (4)

\subsection{Perioperative Renal Protection}

\subsubsection{Risk Factors}

Perioperative renal protection is a great challenge to the anesthesiologist (9). First of all, the anesthesiologist must identify the patient at risk for postoperative renal failure. The risk factors are summarized in Table 3.

NSAIDs are a well-known cause of postoperative renal dysfunction. The mechanisms involve mainly inhibition of prostaglandin synthesis and a decrease in aldosterone, which can lead to potassium retention. The main pathophysiological event is the misbalance between vasoconstrictor and vasodilator mediators, because of inhibition of cyclooxygenase enzymes and decreased synthesis of eicosanoids. These substances play a pivotal role in the regulation of renal function (10). This phenomenon is more significant when several factors are also involved such as preoperative renal dysfunction, surgery stress, and hypovolemia (11).

Radiocontrast dye-induced renal dysfunction can be mediated by an ischemic insult due to vasoconstriction and tubular injury. Recently, it has been reported that the contrast presents an osmotic load to the macula densa, activating the renin-angiotensin system and increasing ischemic damage (12). Amphotericin B creates pores through cell membranes, increased ion leak, and increasing expenditure of energy for sodium pumps. Both mechanisms, vasoconstriction and increased energy demand, can contribute in ischemic damage (13). Aminoglucosides cause cell damage due to the infiltrating proximal tubular 
Table 3. The Risk Factors for Postoperative Renal Failure

\begin{tabular}{lc}
\hline Related to the Patient & Related to the Surgery \\
\hline Pre-existent renal disease & Emergency surgery \\
\hline Increased age & Cardiac surgery \\
\hline Pre-existent cardiac disease and diabetes & Liver transplantation \\
\hline Septic patient & Aortic surgery \\
\hline $\begin{array}{l}\text { Severely reduced perioperative blood } \\
\text { volume }\end{array}$ & Perioperative nephrotoxicity \\
\hline Jaundice and liver dysfunction & Major oncologic surgery \\
\hline Aortic aneurism & NA \\
\hline Malignancy & NA \\
\hline Abbreviation: NA, not available.
\end{tabular}

membrane and proteolytic enzymes (14).

Acute renal failure presents a major complication in intensive care therapy, increasing the mortality likelihood up to $50 \%$. Several risk factors have been recently identified during the patient stay in an intensive care unit. These factors include pre-renal, intra-renal, and post-renal causes. In the majority of cases, pre-renal origin is due to heart failure, hypovolemia, hypotension, sepsis, and bleeding (15). Intra-renal damage is the cause of failure in approximately $10 \%-30 \%$ of patients suffering renal failure and presents in $90 \%$ as acute tubular necrosis. The remaining cases are classified as post-renal causes (calculus).

Cardio-vascular surgery is often associated with postoperative renal failure. Several factors are identified that can contribute to renal damage. These factors include pre-existing renal disease, diabetes, decreased cardiac function, emergency surgery, aortic cross clamping, and cardio-pulmonary bypass (16). The common mechanisms are hypotension, severe bleeding, clots/embolism, prolonged ischemia, and the path physiological changes during cardiopulmonary bypass (non-pulsatile wave of blood circulation and inflammatory response).

Liver transplantation presents a challenge to the anesthesiologist and intensivists. Renal failure is a common complication after this kind of surgery (17). Hypotension, hypovolemia, severe coagulopathy, bleeding, and inflammatory response are the main possible mechanisms. Liver failure, ascites, jaundice, and hepatorenal syndrome can induce renal failure as well.

\subsection{Renal Protection}

Renal protection is generally realized in three steps: maintaining systemic physiological parameters, avoiding nephrotoxicity, and pharmacological protection (18).
Maintaining systemic physiological parameters is guaranteed by maintaining euvolemia, avoiding hypotension and hypertension, avoiding hypoxemia, avoiding severe anemia, and avoiding cardiac depression. Adequate control of hemodynamics, cardiac output, and oxygen delivery can guarantee normal renal function. The most common step is to ensure euvolemia and a normal blood pressure, avoiding both hypotension and hypertension. The patient suffering from chronic renal failure or at risk of acute renal injury has several reasons to be prone to hypotension. These reasons include volume depletion from chronic use of diuretics or dialysis, cardiorenal and renocardiac syndromes, sepsis, mechanical ventilation, vasodilatation due to anesthetic drugs, and autonomic dysreflexia. Maintaining euvolemia is often a difficult issue, because administering liquids is a "double-edged sword." The anesthesiologist can underfill or overfill the vascular bed of the patient, therefore, a careful plan must be considered. The literature recommends a mean arterial pressure ranging from $65-70 \mathrm{mmHg}$, in spite of the idea that autoregulation is lost when the mean arterial pressure drops below 75 - 80 $\mathrm{mmHg}(19,20)$. Monitoring of volemia status, blood pressure, and cardiac output is another critical point. The clinical examination consists of monitoring blood pressure, heart rate, capillary filling, the "raising legs test", and variability of pulse pressure. Clinical examination can be also completed by hemogasanalysis, thoracic X-ray, echocardiography, inferior vena cava index, mix venous saturation, up to Swan Ganz pulmonary catheter, and PICCO. The anesthesiologist must consider a hemoglobin level of approximately $10 \mathrm{~g} / \mathrm{dl}$ and avoid severe anemia episodes. After the volemia restoration, if hypotension is still present, the anesthesiologist may consider vasopressors/inotropes, trying to raise blood pressure without severe renal vasoconstriction. Fluid administration is also recommended in order to prevent acute tubular necrosis after tumor lysis syndrome and contrast dye goal-directed therapy for sepsis management offers a slight reduction in acute kidney failure $(21,22)$. Fluid type is another hot point. It is well known that colloids remain in the intravascular bed more than crystalloids and provide better hemodynamic response. Recently, it has been reported that using hydroxyethyl starch can increase the incidence of renal injury in septic patients $(23,24)$. The combination of crystalloids with colloids seems a more reasonable regimen.

Avoiding nephrotoxicity is an essential step in managing these patients and preventing perioperative renal failure. The anesthesiologist must avoid the use of NSAIDs (25), aminoglucosides (26), vancomycin, immunosuppressant drugs (cyclosporine), contrast solutions (27, 28), angiotensin receptor blocking agents (ARB), and convertase enzyme inhibitor (CEI) drugs. Pharmacological 
optimization includes balanced liquids administration, maintaining hemodynamic parameters, dopamine and fenoldopam, and diuretics (furosemide, mannitol). Pharmacologic protection includes different strategies and drugs. Dopamine has dose-dependent effects on dopaminergic, beta1- and alpha-adrenergic receptors. Its action on DA1 receptors results in increased renal blood flow and provides diuretic and natriuretic effects. Dopamine seems to be able to convert a patient from an oliguric to a nonoliguric state (29). It was recently reported that low-dose dopamine (up to $3 \mathrm{mcg} / \mathrm{kg} /$ minute) may serve as a renal protector agent. Other studies showed no benefits of dopamine use for renal protection. In addition to renal protection, using a low-dose may elicit unexpected tachycardia and hypertension $(30,31)$. Increasing cardiac output can partially explain its effect on renal blood flow.

Another synthetic drug is fenoldopam. Fenoldopam has a similar action as dopamine on DA1 receptors, increasing renal blood flow but without adrenergic activity. However, several studies found no benefits as a renal protector, underlining that its hypotensive effect may be detrimental to renal function (32-34). Morelli et al. found a slight increase on creatinine clearance using low-dose fenoldopam in septic patients, suggesting further studies are needed because of lack of significance (35). Another prestigious study stated that fenoldopam infusion did not reduce the need for renal replacement therapy or risk of 30-day mortality but was associated with an increased rate of hypotension (36).

Nesiritide is a synthetic analogue of a brain natriuretic peptide. This peptide is secreted due to ventricular distention. Nesiritide promotes renal vasodilation, increasing renal blood flow. Nesiritide relieves the heart but has a natriuretic effect as well. Several authors found an increased urine output and a 6-month mortality benefit (37). Further studies appear warranted.

Furosemide and mannitol may limit medullary hypoxia due to reduced oxygen consumption, blocking the sodium/potassium pump and free radical scavenging. $\mathrm{N}$ acetylcysteine is a new antioxidant drug proposed as a renal protector to prevent contrast-induced nephropathy and during cardiopulmonary bypass (38). Calcium blocking agents induce renal vasodilatation, increasing renal blood flow. Calcium blocking agents are proposed to counteract the nephrotoxic effects of calcineurin inhibitors (cyclosporine A, tacrolimus) used for immunosuppression $(39,40)$.

\section{Conclusions}

Nowadays, increasingly aggressive surgery and the safety of anesthesia allow the surgical team to manage pa- tients suffering from CKD. Managing these patients offers unique problems and challenges to the operating team. Good collaboration between different specialties is recommended. Careful preoperative optimization and optimal anesthesia care can guarantee the successful management of patients suffering from CKD undergoing surgery and anesthesia. Maintaining euvolemia, good blood pressure, avoiding nephrotoxicity, and pharmacological protection can decrease the incidence of perioperative renal damage.

\section{Footnote}

Authors' Contribution: Rudin Domi: study design and writing; Gentian Huti: technical review; Hektor Sula, Nehat Baftiu: study design and writing; Myzafer Kaci, Artan Bodeci and Albert Pesha:technical review.

\section{References}

1. National Kidney F. K/DOQI clinical practice guidelines for chronic kidney disease: evaluation, classification, and stratification. Am J Kidney Dis. 2002;39(2 Suppl 1):S1-266. [PubMed: 11904577].

2. Levey AS, Coresh J, Balk E, Kausz AT, Levin A, Steffes MW, et al. National Kidney Foundation practice guidelines for chronic kidney disease: evaluation, classification, and stratification. Ann Intern Med. 2003;139(2):137-47. [PubMed: 12859163].

3. Stevens LA, Coresh J, Greene T, Levey AS. Assessing kidney functionmeasured and estimated glomerular filtration rate. $N$ Engl J Med. 2006;354(23):2473-83. doi: 10.1056/NEJMra054415. [PubMed: 16760447].

4. Bellomo R, Ronco C, Kellum JA, Mehta RL, Palevsky P, Acute Dialysis Quality Initiative W. Acute renal failure - definition, outcome measures, animal models, fluid therapy and information technology needs: the Second International Consensus Conference of the Acute Dialysis Quality Initiative (ADQI) Group. Crit Care. 2004;8(4):R204-12. doi: 10.1186/cc2872. [PubMed: 15312219].

5. Mehta RL, Kellum JA, Shah SV, Molitoris BA, Ronco C, Warnock DG, et al. Acute Kidney Injury Network: report of an initiative to improve outcomes in acute kidney injury. Crit Care. 2007;11(2):R31. doi: 10.1186/cc5713. [PubMed: 17331245 ].

6. Davis JA, May MD, Greenfield BK, Fairey R, Roberts C, Ichikawa G, et al. Contaminant concentrations in sport fish from San Francisco Bay, 1997. Mar Pollut Bull. 2002;44(10):1117-29. [PubMed: 12474973].

7. Jones DR, Lee HT. Surgery in the patient with renal dysfunction. Med Clin North Am. 2009;93(5):1083-93. doi: 10.1016/j.mcna.2009.05.006. [PubMed: 19665621].

8. Wagener G, Brentjens TE. Anesthetic concerns in patients presenting with renal failure. Anesthesiol Clin. 2010;28(1):39-54. doi: 10.1016/j.anclin.2010.01.006. [PubMed: 20400039].

9. Domi R, Ohri I, Andrea G, Sula H, Hafizi A, Janko A, et al. The anesthesiologist s have a role in preventing perioperative renal failure. Anaesth Pain \& Intensive Care. 2012;16:86-91.

10. Kim H, Xu M, Lin Y, Cousins MJ, Eckstein RP, Jordan V, et al. Renal dysfunction associated with the perioperative use of diclofenac. Anesth Analg. 1999;89(4):999-1005. [PubMed: 10512279].

11. Myles PS, Power I. Does ketorolac cause postoperative renal failure: how do we assess the evidence?. Br J Anaesth. 1998;80(4):420-1. [PubMed: 9640143].

12. Brady HBW. In:. 5th ed. Brenner BM, editor. Philadelphia: WB Saunders;1996. pp. 1200-52.Acute Renal Failure. 
13. Sawaya BP, Weihprecht H, Campbell WR, Lorenz JN, Webb RC, Briggs JP, et al. Direct vasoconstriction as a possible cause for amphotericin B-induced nephrotoxicity in rats.JClin Invest. 1991;87(6):2097-107. doi: 10.1172/JCI115240. [PubMed: 1710234].

14. Hladunewich M, Rosenthal MH. Pathophysiology and management of renal insufficiency in the perioperative and critically ill patient. Anesthesiol Clin North America. 2000;18(4):773-89. [PubMed: 11094690].

15. Hanna J, Nichol A. Acute renal failure and the critically ill. Anaesth Intensive Care Medicine. ;13(4):166-70. doi:10.1016/j.mpaic.2012.01.009.

16. Coleman MD, Shaefi S, Sladen RN. Preventing acute kidney injury after cardiac surgery. Curr Opin Anaesthesiol. 2011;24(1):70-6. doi: 10.1097/ACO.0b013e3283422ebc. [PubMed: 21157303].

17. Oltean M, Herlenius G. Renal protection during liver transplantation: an ounce of prevention is worth a pound of cure. Crit Care Med. 2011;39(6):1564-5. doi:10.1097/CCM.0b013e318215bb31. [PubMed: 21610624].

18. Jones DR, Thomas Lee H. Perioper renal prot. Best Practice \& Research Clinical Anaesthesiology. ;22(1):193-208. doi: 10.1016/j.bpa.2007.08.005. [PubMed: 18494397].

19. Ronco C, Bellomo R. Prevention of acute renal failure in the critically ill. Nephron Clin Pract. 2003;93(1):C13-20. [PubMed: 12411754].

20. Lee RW, Di Giantomasso D, May C, Bellomo R. Vasoactive drugs and the kidney. Best Pract Res Clin Anaesthesiol. 2004;18(1):53-74. [PubMed: 14760874].

21. Rivers E, Nguyen B, Havstad S, Ressler J, Muzzin A, Knoblich B, et al. Early goal-directed therapy in the treatment of severe sepsis and septic shock. N Engl J Med. 2001;345(19):1368-77. doi: 10.1056/NEJMoa010307. [PubMed: 11794169].

22. Lin SM, Huang CD, Lin HC, Liu CY, Wang CH, Kuo HP. A modified goal-directed protocol improves clinical outcomes in intensive care unit patients with septic shock: a randomized controlled trial. Shock. 2006;26(6):551-7. doi: 10.1097/01.shk.0000232271.09440.8f. [PubMed: 17117128].

23. Perner A, Haase N, Guttormsen AB, Tenhunen J, Klemenzson G, Aneman A, et al. Hydroxyethyl starch 130/0.42 versus Ringer's acetate in severe sepsis. N Engl J Med. 2012;367(2):124-34. doi: 10.1056/NEJMoa1204242. [PubMed: 22738085].

24. Myburgh JA, Finfer S, Bellomo R, Billot L, Cass A, Gattas D, et al. Hydroxyethyl starch or saline for fluid resuscitation in intensive care. $N$ Engl J Med. 2012;367(20):1901-11. doi: 10.1056/NEJMoa1209759. [PubMed: 23075127].

25. Harirforoosh S, Jamali F. Renal adverse effects of nonsteroidal antiinflammatory drugs. Expert Opin Drug Saf. 2009;8(6):669-81. doi: 10.1517/14740330903311023. [PubMed: 19832117].

26. Nagai J, Tanaka H, Nakanishi N, Murakami T, Takano M. Role of megalin in renal handling of aminoglycosides. Am J Physiol Renal Physiol. 2001;281(2):F337-44. [PubMed: 11457726].

27. Ranucci M, Ballotta A, Kunkl A, De Benedetti D, Kandil H, Conti D, et al. Influence of the timing of cardiac catheterization and the amount of contrast media on acute renal failure after cardiac surgery. Am J Cardiol. 2008;101(8):1112-8. doi: 10.1016/j.amjcard.2007.12.011. [PubMed: 18394443].
28. Weisbord SD, Mor MK, Resnick AL, Hartwig KC, Palevsky PM, Fine MJ. Incidence and outcomes of contrast-induced AKI following computed tomography. Clin J Am Soc Nephrol. 2008;3(5):1274-81. doi: 10.2215/CJN.01260308. [PubMed: 18463172].

29. O'Hara Jr JF. LOW-DOSE “RENAL” DOPAMINE. Anesthesiology Clinics of North America. 2000;18(4):835-51. doi: 10.1016/S0889-8537(05)70197-8. [PubMed: 11094693].

30. Kellum JA, Decker JM. Use of dopamine in acute renal failure: a metaanalysis. Crit care med. 2001;29(8):1526-31. [PubMed: 11505120].

31. Marik PE. Low-dose dopamine: a systematic review. Intensive Care Med. 2002;28(7):877-83. doi: 10.1007/s00134-002-1346-y. [PubMed: 12122525].

32. Oliver Jr WC, Nuttall GA, Cherry KJ, Decker PA, Bower T, Ereth $\mathrm{MH}$. A comparison of fenoldopam with dopamine and sodium nitroprusside in patients undergoing cross-clamping of the abdominal aorta. Anesth Analg. 2006;103(4):833-40. doi: 10.1213/01.ane.0000237273.79553.9e. [PubMed: 17000789].

33. Stone GW, McCullough PA, Tumlin JA, Lepor NE, Madyoon H, Murray $\mathrm{P}$, et al. Fenoldopam mesylate for the prevention of contrastinduced nephropathy: a randomized controlled trial. JAMA. 2003;290(17):2284-91. doi: 10.1001/jama.290.17.2284. [PubMed: 14600187].

34. Landoni G, Biondi-Zoccai GG, Tumlin JA, Bove T, De Luca M, Calabro MG, et al. Beneficial impact of fenoldopam in critically ill patients with or at risk for acute renal failure: a meta-analysis of randomized clinical trials. Am J Kidney Dis. 2007;49(1):56-68. doi: 10.1053/j.ajkd.2006.10.013. [PubMed:17185146].

35. Morelli A, Ricci Z, Bellomo R, Ronco C, Rocco M, Conti G, et al Prophylactic fenoldopam for renal protection in sepsis: a randomized, double-blind, placebo-controlled pilot trial. Crit Care Med. 2005;33(11):2451-6. [PubMed: 16276165].

36. Bove T, Zangrillo A, Guarracino F, Alvaro G, Persi B, Maglioni E, et al Effect of fenoldopam on use of renal replacement therapy among patients with acute kidney injury after cardiac surgery: a randomized clinical trial. JAMA. 2014;312(21):2244-53. doi:10.1001/jama.2014.13573. [PubMed: 25265449].

37. Mentzer RM, Oz MC, Sladen RN, Graeve AH, Hebeler RF, Luber JM, et al. Effects of perioperative nesiritide in patients with left ventricular dysfunction undergoing cardiac surgery:the NAPA Trial. J Am Coll Cardiol. 2007;49(6):716-26. doi: 10.1016/j.jacc.2006.10.048. [PubMed: 17291938].

38. Sisillo E, Ceriani R, Bortone F, Juliano G, Salvi L, Veglia F, et al. N acetylcysteine for prevention of acute renal failure in patients with chronic renal insufficiency undergoing cardiac surgery: a prospective, randomized, clinical trial. Crit Care Med. 2008;36(1):81-6. doi: 10.1097/01.CCM.0000295305.22281.1D. [PubMed: 18090169].

39. Young EWMD, Diab AMD, Kirsh MMMD. Intravenous Diltiazem and Acute Renal Failure After Cardiac Operations. The Ann of Thorac Surgery. ;65(5):1316-9. doi:10.1016/S0003-4975(98)00157-X.

40. Piper SN, Kumle B, Maleck WH, Kiessling AH, Lehmann A, Rohm KD, et al. Diltiazem may preserve renal tubular integrity after cardiac surgery. Can J Anaesth. 2003;50(3):285-92. doi: 10.1007/BF03017799. [PubMed: 12620953]. 